\title{
As ações populares previstas pelo código civil e a evolução do direito administrativo colombiano*
}

\section{The Popular Actions Provided for in the Civil Code and the Evolution of Colombian Administrative Law}

SUMARIO

1. A exclusividade da administração pública na gestão dos bens de uso público. 1.1. A ausência de exclusividade da administração pública no momento de elaboração do código civil colombiano. 1.1.1. A administração não dispunha de uma habilitação exclusiva para velar pela conservação dos bens de uso público. 1.1.2. A administração pública não dispunha de um dever exclusivo de reparar os bens de uso público danificados.1.2. A afirmação da exclusividade da administração pública e sua incidência no campo das ações populares. 1.3. O entendimento da Corte Suprema de Justicia sobre as ações populares sob o prisma da exclusividade da administração pública. 2. A evolução do contencioso administrativo. Conclusão.

\section{RESUMEN}

Mientras la doctrina colombiana entiende que las acciones populares del Código Civil fueron "inexplicablemente relegadas al olvido", la comparación de la evolución del derecho administrativo colombiano con el derecho brasileño lleva a otra conclusión. Las acciones populares existentes a mediados del siglo XIX hacían parte de un complejo sistema que tenía dos ideas centrales: la administración pública no era la única habilitada para velar por los bienes de

* Todas as citações de legislação, jurisprudência e doutrina contidas no presente estudo conservam a grafia original e não foram atualizadas pelas novas regras ortográficas.

Recibido el 9 de diciembre de 2014, aprobado el 20 de febrero de 2015.

Para citar el artículo: Tн. M. DA CostA, As ações populares previstas pelo código civil e a evolução do direito administrativo colombiano. Revista Derecho del Estado n. ${ }^{\circ} 34$, Universidad Externado de Colombia, enero junio de 2015, pp. 61-76. DOI: 10.18601/01229893.n34.04

** Doutorando em regime de dupla titulação (cotutela) na Université Paris I Panthéon-Sorbonne e na Universidade de São Paulo. O autor gostaria de registrar seus agradecimentos ao Departamento de Derecho Constitucional e ao Departamento de Derecho Administrativo da Universidad Externado de Colombia pela honra de ter sido "investigador invitado" de fevereiro a agosto de 2011. Endereço eletrônico para contato: costathales@yahoo.fr 
uso público y no era la única que debía contribuir a su reparación (existencia de lo que el derecho vigente llamaba "servicio personal subsidiario"). A partir de finales del siglo xIx, la afirmación de la exclusividad de la administración en la gestión de los bienes de uso público y la creación del contencioso administrativo llevaron a la jurisprudencia a restringir cada vez más el ámbito de las acciones populares del Código Civil.

PALABRAS CLAVE

Acciones populares, código civil, administración pública, exclusividad, contencioso administrativo.

\section{ABSTRACT}

While Colombian jurisprudence suggest that the popular actions provided for in the civil code have been 'inexplicably forgotten', the evolution of Colombian administrative law, when compared to Brazilian law, leads to another conclusion. The popular actions existing in the middle of the 19th century were a part of a complex system based on two main ideas: public administration had no exclusive jurisdiction on things for public use and it had no exclusive duty to preserve these things (existence of what Colombian Law used to call the 'subsidiary personal service'). From the end of the 19th century, the consolidation of public administration's exclusive jurisdiction on things for public use and the creation of administrative judges lead Colombian courts to restrict gradually the field of the popular actions enunciated in the civil code.

\section{KEYWORDS}

Popular actions, civil code, Public Administration, exclusivity, Administrative Judges.

Ao deparar-se com o fato de que, durante o século xx, são raros os casos práticos de ações populares fundadas no código civil de 1873, parte da doutrina colombiana tem tendência a considerar que elas teriam sido "inexplicablemente relegadas al olvido." $\mathrm{O}$ objetivo deste estudo é apresentar uma

1 GERMÁn S ARMIENTO. Las acciones populares en el derecho privado colombiano. Bogotá, 1988, p. 8-16. A opinião desse autor é citada em JuAn CARlos GuaYACÁn Ortiz. Las acciones populares y de grupo frente a las acciones colectivas. Bogotá: Externado, 2013, p. 219-220. Ao citar essa opinião, Guayacán Ortiz acrescenta: "Cuando en 1887 el legislador colombiano decide adoptar como código civil la codificación hecha por BELLo en Chile, los tiempos para 
interpretação diferente e, para tanto, partiremos de uma breve comparação com o código civil brasileiro.

Contrariamente ao código colombiano, que prevê as ações populares nos artigos 1005, 2355 e 2359, o primeiro código civil brasileiro, aprovado em 1916, nada dizia sobre esta modalidade de acesso à justiça. Durante a elaboração deste código, houve um debate acerca da inclusão ou não de um artigo prevendo as ações populares. Um dos membros da comissão redatora do projeto, ANDRADE FIGUEIREDo, manifestou-se favoravelmente a esta inclusão, mas não obteve a adesão dos demais integrantes desta comissão. Prevaleceu a opinião de Clóvis BEVILACQUA, segundo a qual « se compreende [a existência de ações populares] em um estado do direito em que a organização política não está suficientemente desenvolvida, de modo que seja indispensável que os particulares estejam velando pelos interesses públicos $»^{2}$. Este já não seria, porém, o caso do Brasil, na opinião dos integrantes desta comissão. MANUEL Aureliano DE GuSMÃo sintetizou com clareza o pensamento dominante na passagem do século XIX ao XX: «No estado actual, porém, não só do nosso Direito, como do Direito da quasi totalidade das nações civilizadas, não mais ha logar ao exercicio das acções populares; e a razão é que (...) na organização juridica hodierna, por um lado, os actos que, no Direito Romano, autorizavam as acções populares, ou passaram a constituir crimes definidos e punidos pelas leis penaes, ou a ser objecto de leis de policia, de leis provinciaes, communaes ou municipaes, e por outro lado a funcção judiciaria de velar pela guarda e conservação dos bens publicos e de defender, em juizo, os interesses sociaes e collectivos é exercida pelos representantes do ministerio publico, para tal fim creado e instituido no organismo politico da generalidade dos povos cultos $»^{3}$

É procedente a observação deste autor no sentido de que os atos que anteriormente autorizavam as ações populares passaram a ser previstos como crimes ou a ser objeto de leis de polícia. A legislação brasileira em vigor ao final do século XIX fornece exemplos claros a respeito dessa evolução, tanto no âmbito do direito penal quanto na esfera do direito administrativo.

el ejercicio de las acciones populares aún no estaban maduros; hasta donde llega nuestra información no existen huellas de estas acciones en la jurisprudencia, y, a nivel de doctrina, la primera manifestación que encontramos data de 1988, cuando se advertía de la existencia de este valioso instrumento".

2 Projecto do codigo civil brazileiro. Trabalhos da Comissão Especial da Câmara dos Deputados. Rio de Janeiro: Imprensa Nacional, 1902, vol. IV, p. 221-222.

3 Manuel Aureliano de Gusmão. Processo civil e commercial. 4. ed. São Paulo: Saraiva, 1939, p. 303. No mesmo sentido, v. Clóvis BevilacQua. Teoria geral do direito civil, 2. ed. Rio de Janeiro: Editora Rio, 1980, p. 279. Os debates ocorridos no momento da elaboração do código civil de 1916 podem ser encontrados em Projecto do codigo civil brazileiro. Trabalhos da Comissão Especial da Câmara dos Deputados. Rio de Janeiro: Imprensa Nacional, 1902, vol. Iv, p. 221-222. 
O artigo 152 do código penal brasileiro de 1890, por exemplo, previa uma pena de prisão para o fato de «[d]estruir, ou damnificar, qualquer parte de estrada ou via de communicação de uso publico, obstando ou interrompendo o transito por ella...» - fato que, no direito romano, podia ser atacado por meio de ação popular. Quanto ao direito administrativo, convém citar o artigo 45 da lei $\mathrm{n}^{\mathrm{o}} 16$ de 13 de novembro de 1891 do Estado de São Paulo, segundo o qual "[é] da exclusiva competencia das camaras a administração e conservação dos bens municipaes, entre os quaes se comprehendem tanto os proprios municipaes como os de uso commum dos moradores." A afirmação de uma competência "exclusiva" da administração pública em matéria de gestão dos bens de uso público é especialmente reveladora da superação das ações populares, tal como será demonstrado adiante.

O importante neste momento é destacar que os redatores do código civil de 1916 preferiram não criar regras nas áreas já disciplinadas pelo direito penal e pelo direito administrativo. Esta escolha da comissão redatora do có0digo civil é a razão pela qual o código brasileiro é significativamente mais curto do que o de outros países, como a Colômbia ${ }^{4}$.

A evolução descrita acima - segundo a qual os atos que outrora davam azo às ações populares estavam agora disciplinados pelo direito penal e pelo direito administrativo - permite entender a razão pela qual o código brasileiro de 1916 adotou uma concepção do acesso à justiça focada no interesse individual. Segundo o art. 76 desse código, "[p]ara propor, ou contestar uma ação, é necessário ter legitimo interesse econômico, ou moral. Parágrafo único. $O$ interesse moral só autoriza a ação quando toque diretamente ao autor, ou á sua família."

Este é, em rápidas palavras, o pensamento que fez com que o código civil de 1916 não previsse as ações populares.

Voltando agora os olhos para o direito colombiano, o caso brasileiro traz uma perspectiva interessante de análise: o direito penal e o direito administrativo teriam exercido alguma influência sobre a prática das ações populares previstas pelo código civil de 1873 ? De que maneira essas ações teriam sido acolhidas pela jurisprudência colombiana no final do século XIX e na primeira metade do século $\mathrm{xx}$ ?

São estas as questões que serão examinadas no âmbito deste estudo.

A questão relativa ao direito penal pode ser tratada rapidamente. A legislação penal permaneceu, no tema dos bens de uso público, bastante modesta. O código de 1890 (lei n ${ }^{\circ} 19$ de 18 de outubro de 1890) não continha nenhum artigo sobre esses bens, contrariamente ao código penal brasileiro adotado no mesmo ano. A única disposição do código colombiano de 1890 suscetível

4 O código civil brasileiro de 1916 contém 1807 artigos, enquanto que o colombiano contém 2684. 
de ser relacionada com os bens de uso público é a que criminalizava o dano causado às vias férreas (art. 869). O código penal de 1936 (lei n ${ }^{\circ} 95$ de 24 de abril de 1936) retomou esta regra em termos muito parecidos e acrescentou o dano às vias para automóveis (art. 256). É somente com o código penal de 1980 que a matéria penal foi ampliada a ponto de criminalizar o dano causado aos bens de uso público de modo geral ${ }^{5}$. O âmbito penal permaneceu, como se vê, bastante limitado e não chegou a representar, durante muito tempo, qualquer obstáculo à opção do legislador civil de 1873 de prever ações populares em matéria de bens de uso público.

A mesma timidez não se verificou, porém, no caso do direito administrativo, que teve um desenvolvimento muito importante em dois campos fundamentais: a exclusividade da administração pública na gestão dos bens de uso público (1) e a repartição de competências entre juiz ordinário e juiz administrativo (2).

1. A EXCLUSIVIDADE DA ADMINISTRAÇÃO PÚBLICA NA GESTÃO DOS BENS DE USO PÚBLICO

\subsection{A ausência de exclusividade da administração pública no momento de elaboração do código civil colombiano}

A ausência de exclusividade da administração pública na gestão dos bens de uso público revela-se em dois âmbitos distintos: o fato de que ela não era a única habilitada a velar pela conservação destes bens (1.1.1) e o fato de que ela não era a única a dever reparar os bens que tivessem sido danificados (1.1.2).

1.1.1. A administração não dispunha de uma habilitação exclusiva para velar pela conservação dos bens de uso público

O direito colombiano não demorou a atribuir à polícia administrativa poderes de gestão dos bens de uso público. A lei de 18 de maio de 1841, por exemplo, já previa em seu artigo 79 que "Cuando haya dentro de las poblaciones algún edificio vencido ó que amenace ruina, i que por su causa pueda peligrar la seguridad de las personas, los jefes de policía deben requerir à su dueño para que lo descargue ó derribe; i no haciéndolo dentro de tercero dia, lo mandarán hacer à costa del dueño. (...)"6

$5 \quad$ O artigo 371.4 do código de 1980 (decreto-lei no 100 de 23 de janeiro de 1980) é, de fato, o primeiro a consagrar a categoria dos bens de uso público como um objeto específico do delito de dano. Ele dispõe que a pena prevista para esse delito será majorada de até um terço se o dano tiver sido causado a um "bien de uso público o de utilidad social".

6 Redação da lei tal como consta da Recopilación de leyes de la nueva granada. Bogotá: Ediciones Academia Colombiana de Jurisprudencia, 2012. 
Observe-se que, ao conceder essa atribuição à polícia administrativa, a lei de 1841 não afirmava que o fazia a título exclusivo. Deixava-se, assim, aberta a possibilidade de que outras leis previssem outros meios de obter o mesmo resultado.

Era o que ocorria com a via judicial. Segundo as Siete Partidas, texto que permanecia em vigor nas primeiras décadas posteriores à independência colombiana ${ }^{7}$, "[a]brense á las veces las labores nuevas, porque se fienden los cimientos, ó porque fueron fechos falsamente ó por flaqueza de la labor; et otrosi los edeficios antiguos fallescen et quiérense derribar por vejez: et los vecinos que están acerca dellos témense de rescebir ende daño. Sobre tal razón como esta decimos quel judgador del logar puede et debe mandar á los señores de aquellos edeficios que los enderescen ó que los derriben" (lei x do título XXXII da Partida III).

Quando ANDRÉs BeLLo elaborou seu projeto de código civil, incluiu três artigos em que se vê claramente a influência das Siete Partidas": "La municipalidad i cualquiera persona del pueblo podrá intentar la querella de que se trata en los tres artículos precedentes, siempre que del mal estado del edificio pueda seguirse daño, no solo a los vecinos, sino a los transeúntes. La misma querella, i con los mismos efectos, podrá ser intentada por cualquier persona particular, siempre que del mal estado del tal edificio pudiere resultar daño a las cosas de uso público, como calles, caminos, etc."10; "Si hubiere alguna cosa que, de la parte superior de un edificio o de otro paraje elevado, amenace caída i daño, podrá ser obligado a removerla el dueño del edificio, o su inquilino, o la persona a quien perteneciere la cosa o que se sirviere de ella; i cualquiera del pueblo tendrá derecho para pedir la remocion" 11 " "Por regla general, se concede accion popular en todos los

7 A vigência das Siete Partidas na Colômbia é expressamente reconhecida pela Ley de Procedimiento Civil sancionada em 13 de maio de 1825.

8 Redação conforme à seguinte edição: Las Siete Partidas del Rey Don Alfonso El Sabio, cotejadas con varios codices antiguos por la Real Academia de la Historia. Madrid: Imprenta Real, 1807.

9 Bello sempre deixou clara toda sua admiração pelas Siete Partidas. Ao publicar seu primeiro projeto de código civil, afirmou o seguinte: "nos atrevemos a decir que esta obra es de menor magnitud i dificultad para nosotros que lo fué la del código de las SIETE PARTIDAS, en el siglo décimotercio: lo primero, porque las innovaciones de que ahora se trata son mucho ménos considerables, supuesto que no se piensa en crear, sino en correjir i simplificar" (citado por Miguel Luis Amunátegui. "Introduccion", in Obras completas. Vol. XI. Proyectos de código civil. Santiago: Pedro G. Ramirez, 1887, p. vIII).

10 Trata-se da redação do artigo 1093, primeira parte, do projeto de 1853 (in Obras completas. Vol. XII. Proyecto de código civil (1853). Santiago: Pedro G. Ramirez, 1888, p. 246-249). O código civil colombiano incorporou esta regra em seu artigo 1005.

11 Trata-se da redação do artigo 2492 do projeto de 1853 (Ibid., p. 590-591). O projeto anterior, de 1847, continha previsão muito semelhante no art. 670, segunda parte (in Obras completas. Vol. XI. Proyectos de código civil. Santiago: Pedro G. Ramirez, 1887, p. 596-597). O código civil colombiano incorporou esta regra em seu artigo 2355. 
casos de daño contingente que por imprudencia o negligencia de alguien amenace a personas indeterminadas (...)"12.

Esses textos - a lei colombiana de 1841, de um lado, e as Siete Partidas e o projeto de Bello, de outro - apresentam semelhanças em dois pontos de fundamental importância. O primeiro é que todos eles revelam uma preocupação com a segurança dos que transitam à proximidade de um edifício em ruínas e buscam evitar que um dano seja causado a essas pessoas: a lei de 1841 menciona o edifício que "pueda peligrar la seguridad de las personas", enquanto que a Partida III fala dos "vecinos" que "témense de rescebir ende daño" e BELLO refere-se ao risco de que "pueda seguirse daño" ou "pudiere resultar daño", bem como à coisa que "amenace caída $i$ daño" e ao "daño contingente".

O segundo ponto em que esses textos se assemelham é que todos preveem a possibilidade de impor o reparo ou a derrubada dos edifícios em ruínas, mas nenhum deles atribui essa competência a uma só autoridade: o texto colombiano diz que a edição desta ordem é de competência da autoridade administrativa; as Siete Partidas e o projeto de Bello dizem que a mesma ordem cabe ao juiz, uma vez acionado por um "vecino" ou "cualquiera del pueblo".

Percebe-se, então, a primeira faceta da ausência de exclusividade da administração pública na gestão dos bens de uso público: era possível que a mesma medida fosse adotada por mais de uma autoridade.

1.1.2. A administração pública não dispunha de um dever exclusivo de reparar os bens de uso público danificados

A segunda faceta da ausência de exclusividade da administração pública na gestão dos bens de uso público está ligada ao reparo dos bens de uso público danificados. A lei de 19 de maio de 1834 previa que, quando os recursos públicos não fossem suficientes "para los gastos necesarios i frecuentes que exija la reparacion de caminos, calzadas, puentes, tambos i posadas, la limpieza de los ríos $i$ caños navegables, i la conservacion de otras obras necesarias para la facilidad de las comunicaciones; todos los habitantes de la respectiva ciudad, villa ó distrito parroquial son obligados á concurrir á estos trabajos con su servicio personal" (art. 206).

O "servicio personal subsidiario para la reparacion de los caminos i obras públicas" (título xi da lei de 1834) visava a que os bens de uso público "se conserven siempre en el mejor pie posible" e a que "se hagan los reparos

12 Trata-se da redação do artigo 2497 do projeto de 1853 (Ibid.). O projeto de 1847 continha previsão semelhante (cf. art. $671 \mathrm{ibid}$.), a qual revela ainda mais claramente a profunda ligação entre esse artigo e o art. 670 do projeto de 1847 (correspondente ao art. 2492 do projeto de 1853). O código civil colombiano incorporou esta regra em seu artigo 2359. 
convenientes inmediatamente que tenga noticia de cualquier daño" (art. 216 da mesma lei).

Segundo o art. 211 do mesmo texto, "[a ]nualmente forman los alcaldes una lista general de todos los habitantes de la ciudad, villa ó distrito parroquial que estan obligados al servicio personal" e, nos termos do art. 212, "[o]cho dias antes de emprenderse cualquiera reparo ú obra de las prevenidas en el artículo 207, los alcaldes fijan la lista particular de los que en aquella vez. deben prestar el servicio personal, haciéndolos tambien citar personalmente".

Uma regra semelhante já existia nas Siete Partidas. No texto da lei xx do título XXXII da Partida III, já aparece muito claramente a relação entre os danos causados aos bens de uso público e a possibilidade de exigir dos cidadãos que supram eventual falta de recursos públicos para reparar o bem afetado. Segundo este texto, "Apostura et nobleza del regno es mantener los castiellos, et los muros de las villas, et las otras fortalezas, et las calzadas, et las puentes et los caños de las villas, de manera que non se derriben nin se desfaga." O mesmo texto prossegue dizendo que "la guarda et la femencia destas labores pertenesce al rey", o qual "debe hi poner homes señalados et entendudos en estas cosas et acuciosos, et mandarles que fagan lealmiente el reparamiento que fuere meester á las cosas que desuso dixiemos." No entanto, prossegue a mesma lei xx, "si en las cibdades ó en las villas do han meester de facer algunas destas labores, si han rendas apartadas de comun, deben hi seer primeramiente despendidas: et si non complieren ó non fuese hi alguna cosa comunal, entonce deben los moradores de aquel logar pechar comunalmiente cada uno por lo que hobiere fasta que ayunten tanta quantia de que se pueda complir la labor."

A lei colombiana de 1834 foi até mais longe do que as Siete Partidas, na medida em que abriu a possibilidade de que os cidadãos tivessem que realizar pessoalmente o reparo, enquanto que o texto espanhol somente falava de uma contribuição econômica para complementar os recursos públicos. Mas a ideia, em sua essência, é a mesma nos dois textos: frente à necessidade de reparar o dano causado a um bem de uso público, os cidadãos podem ser obrigados a dar uma contribuição pessoal, caso os recursos públicos sejam insuficientes.

Esta obrigação subsidiária que existia para os habitantes de determinada parte do território permite entender que a ação popular para proteção dos bens de uso público e para assegurar a segurança dos que transitam por eles inseria-se, na verdade, em um contexto bastante específico. Não se tratava de disposição isolada visando apenas a dar aos cidadãos uma via de participação na gestão das questões de interesse geral. Tratava-se, de modo muito mais profundo, de um mecanismo permitindo ao cidadão exigir em juízo o reparo do bem de uso público afetado a fim de evitar que, na hipótese de não haver recursos públicos suficientes para o restabelecimento deste bem, ele viesse a ser convocado a fazer o reparo pessoalmente, através do "servicio 
personal subsidiario". Logo, o ajuizamento da ação popular não era um ato totalmente desinteressado do cidadão. O autor da ação agia, sem dúvida, no interesse de todos, mas também em seu próprio interesse, pois ao fazer com que o responsável pelo dano fosse condenado a repará-lo, o cidadão evitava que lhe obrigassem a fazer pessoalmente a obra necessária para o reparo do bem de uso público.

Uma vez estabelecido que a ação popular inseria-se em um contexto bastante específico, cumpre analisar agora o que ocorreu no momento em que esse contexto foi modificado na segunda metade do século XIX.

\subsection{A afirmação da exclusividade da administração pública e sua incidência no campo das ações populares}

A segunda metade do século XIX caracteriza-se não apenas pela multiplicação das competências da administração pública, mas também, e sobretudo, pela afirmação de sua exclusividade no exercício de tais competências.

O código de policía de Cundinamarca é especialmente revelador desta inovação. Ele possui um número muito maior de artigos do que a lei de 1841, que versava, ela também, sobre "policía jeneral"13. Mais fundamentalmente, é possível encontrar várias vezes o vocábulo "exclusivo" ao longo do texto de Cundinamarca, o que é uma inovação significativa com relação à lei de 1841 .

De fato, no que diz respeito a evitar danos e preservar a segurança dos que transitam pelos bens de uso público, convém destacar o art. 320 deste código: "Las vías públicas son de cargo exclusivo de la Administración pública, la cual se ocupa: $1^{\circ}$. En la conservación de su uso público, impidiendo toda usurpación que pueda hacerse y todo daño que pueda causarse en ellas; $2^{\circ}$. En la libertad y seguridad de su transito; $3^{\circ}$. En la comodidad y hornato para hacer su tránsito fácil y agradable; $y 4^{\circ}$. En su composición y mejora, creando recursos para este objeto y disponiendo el modo de aplicarlos." 14

É importante que se compreenda a afirmação da exclusividade da administração pública sob a ótica da situação vigente na primeira metade do século XIX, tal como descrita acima. A exclusividade significava não apenas que competia à administração pública e a nenhuma outra autoridade a gestão das vias públicas para a "conservación de su uso público" e para a "libertad y seguridad de su transito", mas também que a administração não podia mais omitir-se de cumprir suas obrigações. $\mathrm{O}$ código de Cundinamarca prevê que

13 O código de policía de Cundinamarca (ordenança de 8 de janeiro de 1859 modificada pela ordenança $\mathrm{n}^{\circ} 38$ de 1888) tem aproximadamente 700 artigos divididos em três livros, cada um deles contendo diversos títulos.

14 Redação do código de policía de Cundinamarca de acordo com o livro publicado sob a direção de RAmón Gómez Cuéllar e FABIo Hernández. Bogota: Imprenta de "Sur América", 1912. 
a administração pública se ocupa também, e "de cargo exclusivo", da "composición y mejora" das vias públicas "creando recursos para este objeto". Logo, não lhe era mais possível alegar a falta de recursos para deixar nas mãos dos cidadãos - através da execução do "servicio personal subsidiario" - a execução de uma tarefa que lhe competia agora a título exclusivo.

Este é o significado profundo da consagração da exclusividade da administração pública: reservar-lhe determinada atribuição, mas, ao mesmo tempo, imputar-lhe a responsabilidade exclusiva no exercício concreto da competência que lhe foi outorgada.

Uma vez compreendido esse significado, é possível perceber que a exclusividade da administração pública opõe-se à ideia de base da ação popular. De fato, as ações populares previstas pelo código civil permitem que o cidadão peça ao juiz que adote uma medida similar àquela que a administração poderia ou deveria ter adotado. Abre-se, assim, a possibilidade de que o cidadão, juntamente com o juiz, possa controlar a ação ou a omissão da administração e, por vezes, substituir-se à administração. Ora, a partir do momento em que se afirma a exclusividade da administração pública, essa substituição torna-se problemática.

A comparação do art. 320 do código de policía de Cundinamarca com o art. 1005 do código civil ${ }^{15}$ permite entender o que se está a dizer. Essa comparação revela que estes textos guardam certa semelhança em alguns aspectos, mas também evidencia uma diferença profunda entre eles.

A semelhança é dupla e consiste no seguinte: de um lado, afirma-se a ideia de que é possível ordenar a demolição ou o reparo de um edifício; de outro lado, afirma-se que essa ordem visa a garantir a segurança dos que transitam pelos bens de uso público.

No entanto, há uma diferença fundamental entre esses textos, diferença que não existia entre, de um lado, a lei de 1841 e, de outro lado, o texto das Siete Partidas e o do projeto de Bello: o código de Cundinamarca afirma que a competência para impor a demolição ou o reparo de um edifício é exclusiva da administração pública, enquanto que o código civil apresenta uma alternativa: ou a municipalidade ou qualquer pessoa do povo poderá pedir ao juiz que ordene a demolição ou o reparo de um edifício.

Fica evidente a partir dessa análise que a exclusividade da administração pública e a alternativa municipalidade/qualquer pessoa do povo são postulados contraditórios entre si. Por via de consequência, quanto mais força for conferida à exclusividade da administração pública, menor será o campo em que as ações populares podem ser exercidas.

15 Segundo o art. 1005, "La municipalidad y cualquiera persona del pueblo tendrá en favor de los caminos, plazas u otros lugares de uso público, y para la seguridad de los que transitan por ellos, los derechos concedidos a los dueños de heredades o edificios privados. Y siempre que a consecuencia de una acción popular haya de demolerse o enmendarse una construcción...". 
O estudo da jurisprudência desenvolvida pela Corte Suprema de Justicia permite constatar que foi exatamente o que ocorreu.

1.3. O entendimento da Corte Suprema de Justicia sobre as ações populares sob o prisma da exclusividade da administração pública

Pouco tempo depois da adoção da Constituição de 1886 e da reforma do código de policía de Cundinamarca, chegou até a Corte Suprema de Justicia um caso que lhe permitiu esclarecer seu entendimento acerca dos efeitos que a exclusividade da administração pública exercia sobre as ações populares.

$\mathrm{O}$ departamento de Cundinamarca havia celebrado um contrato para a construção de uma via pública entre Villeta e o rio Magdalena. Em razão de desacordos com o particular contratado, o ente público ajuizou uma ação pedindo que fosse declarada a resolução e a caducidade do contrato em questão, liberando-se o departamento das obrigações que havia contratado.

Um cidadão quis ingressar em juízo como litisconsorte (parte coadyuvante) do departamento e foi admitido enquanto tal pelo Tribunal Superior de Cundinamarca, sob fundamento dos artigos 1005 e 2359 do código civil. No entanto, a Corte Suprema de Justicia reformou a decisão do tribunal de origem, sob o seguinte fundamento: "Si la acción entablada por el Departamento de Cundinamarca tuviera el carácter de popular que erróneamente se le supone, (...) habría que reconocer que un simple particular puede demandar á todo el que haya celebrado un contrato con el Gobierno (...) para que se declare la caducidad del contrato, la indemnización de perjuicios por su falta de cumplimiento, ó en fin, ejercer todas las acciones que natural y legalmente corresponden al que celebró el contrato, lo que evidentemente es absurdo y contrario á las leyes que organizan las entidades políticas, sus facultades, sus derechos, sus obligaciones y su representación en juicio. No serían yá las Corporaciones y funcionarios á quienes la ley ha encomendado la administración de los intereses comunales y conferido la personalidad jurídica á quienes tocaría exclusivamente_deliberar y resolver sobre la necesidad y oportunidad del establecimiento de una acción judicial y sobre el modo de promoverla ó proseguirla, sino también á cualquier particular, quien, á pretexto de ser contribuyente ó interesado en la cosa pública, podría tomar participación directa en negocios que están encomendados exclusivamente á ciertas Corporaciones ó empleados que ejercen los derechos de la comunidad.

La acción popular no nace siempre del interés más ó menos directo que una persona pueda tener en alguna cosa, hecho ú omisión: esa acción sólo tiene lugar en los casos expresamente previstos en la ley" 16.

16 Corte Suprema de Justicia, acórdão de 24 de setembro de 1891, in Gaceta Judicial, t. VI, 1891, p. 333-335 (o itálico é nosso). 
Como se pode ver, a exclusividade da administração foi determinante para a solução do caso concreto. A Corte Suprema de Justicia empregou essa palavra duas vezes a fim de justificar a interpretação restritiva que estava dando às ações populares previstas pelo código civil. Entendeu-se que essas ações somente seriam admitidas nos casos expressamente previstos, o que levava a assegurar à administração pública a exclusividade na tomada de decisões em todos os demais campos não cobertos pelas ações populares. Por outras palavras, nas matérias em que houvesse duplicidade de regras, o previsto no código de policía de Cundinamarca valeria como regra geral; o código civil seria a exceção.

A resistência da Corte Suprema de Justicia frente às ações populares era tão grande que, mesmo nos casos expressamente previstos pelo código civil, o alto tribunal revelava certo desconforto em julgar procedente a ação. Evidentemente, como os artigos 1005, 2355 e 2359 do código civil não haviam sido revogados, os magistrados não podiam deixar de aplicá-los. Mas é interessante observar que, mesmo quando julgava o pedido da ação popular procedente, a Corte Suprema de Justicia chamava a atenção para o fato de que a questão envolvia o exercício de competências administrativas e que, por via de consequência, o caso poderia ser resolvido na esfera administrativa, sem que fosse necessário levar o caso perante a justiça.

Com efeito, um caso julgado em 23 de abril de 1941 enfrentou a questão da extração de cascalho com explosivos no perímetro urbano de Chiquinquirá. Com fundamento no art. 2359 do código civil, um cidadão havia ajuizado uma ação popular contra o Departamento de Boyacá para evitar a concretização de um dano contingente. Segundo a Corte Suprema de Justicia, " $[$ s] i (...) la explotación de que se trata (...) constituye grandísima falta de previsión, incalificable imprudencia, no tendría justificación desconocer el derecho de cualquier vecino a pedir que se suspenda un trabajo que constituye permanente amenaza, si se sigue ejecutando en forma imprudente." No entanto, na frase imediatamente seguinte, a Corte acrescentou: "Esta es una cuestión que podría decidirse por las autoridades administrativas, ya que en todos los Códigos de Policía departamentales, se establece la prohibición de ejecutar trabajos de la índole de la referida explotación, dentro del perímetro urbano de las poblaciones, sin las debidas precauciones." ${ }^{17}$.

Como se vê, até o momento em que este caso foi julgado, as ações populares previstas pelo código civil ainda eram admitidas, mas não eram estritamente necessárias, pois era possível obter o mesmo resultado por via administrativa.

17 Corte Suprema de Justicia, acórdão de 23 de abril de 1941, in Gaceta Judicial, t. LI, p. 437-456. 
Esta situação, já bastante limitadora das ações populares, agravou-se com a evolução da repartição de competências entre juiz ordinário e juiz administrativo.

\section{A EVOLUÇÃO DO CONTENCIOSO ADMINISTRATIVO}

A criação da jurisdição do contencioso administrativo em 1913 não afetou de imediato a competência do juiz ordinário para conhecer das ações populares previstas pelo código civil. A prova está no acórdão já citado de 23 de abril de 1941, no qual a Corte Suprema de Justicia reconheceu-se competente para julgar a ação popular e ordenou ao departamento de Boyacá que deixasse de extrair cascalho com métodos que representassem uma ameaça para a segurança dos transeuntes.

No entanto, em 24 de dezembro deste mesmo ano, foi adotada a lei $\mathrm{n}^{\circ} 167$ que atribuiu novas competências ao juiz administrativo. Entre as inovações trazidas por essa lei encontra-se o aumento da lista dos atos que estavam submetidos ao controle do juiz administrativo (artigos 34 e 54). Essa medida suscitou a reação da Corte Suprema de Justicia, que declarou a inexequibilidade da lei $\mathrm{n}^{\circ} 167$ de 1941, por considerá-la contrária ao artigo 41 do acto legislativo $\mathrm{n}^{\mathrm{o}} 3$ de $1910^{18}$. Uma modificação da Constituição sobreveio em 1945 a fim de confirmar a transferência ao juiz administrativo de diversas competências até então reservadas à Corte Suprema de Justicia ${ }^{19}$.

Face a um movimento tão claro e persistente de transferência de competências ao juiz administrativo, é possível constatar, ao final dos anos 1940, certa hesitação do juiz ordinário a pronunciar-se sobre os casos envolvendo a administração pública. Uma ação popular julgada em 6 de agosto de 1947 é bastante representativa desta nova orientação jurisprudencial.

Nesse caso, o autor queixava-se do estado de conservação de uma ponte que, dizia ele, ameaçava a segurança dos transeuntes. Pediu-se ao juiz ordinário que ordenasse ao departamento de Antioquia o reparo da ponte em questão. O artigo 1005 do código civil prevê expressamente a ação popular "para la seguridad de los que transitan" pelos bens de uso público e prevê que o juiz pode ordenar a "enmienda de una construcción". Tudo parecia conduzir a que o pedido do autor fosse julgado procedente.

No entanto, segundo a Corte Suprema de Justicia, a ação popular prevista por esse artigo somente seria admissível se a origem da ameaça para a segurança dos que transitam pelos "caminos, plazas u otros lugares de uso público" fosse um edifício privado. Se a origem da ameaça fosse um bem

18 Corte Suprema de Justicia, acórdão de 7 de julho de 1942, in Gaceta Judicial, t. LIII, 1942-1943,p. 231-240. O artigo 41 do acto legislativo $\mathrm{n}^{\circ} 3$ de 1910 especificava as competências da Corte Suprema de Justicia.

19 É o que prevê o artigo 41 do acto legislativo $\mathrm{n}^{\circ} 1$ de 16 de fevereiro de 1945. 
público, a ação popular seria inadmissível. Como este era o caso dos autos, a Corte Suprema de Justicia considerou que "la única relación posible entre los particulares y el Estado en razón de las posibles consecuencas de la falta de cuidado de las entidades públicas en el mantenimiento seguro y adecuado de los bienes de uso común" ${ }^{20}$ seria a ação de indenização a ser ajuizada pela vítima direta.

Sem dizê-lo de maneira clara, a Corte Suprema de Justicia parece tirar as consequências da transferência progressiva de competências em favor do juiz administrativo: o juiz ordinário não seria mais competente para impor comportamentos às autoridades administrativas, embora ainda o fosse quando do julgamento datado de 23 de abril de 1941 examinado logo acima. As ações populares agora somente permitiriam ao juiz ordinário impor o reparo de um edifício em ruínas aos particulares, não à administração pública.

Se a Corte Suprema de Justicia já procurava, em 1947, reduzir o âmbito de aplicação das ações populares para evitar intrusões nas competências do juiz administrativo, isso se tornou ainda mais evidente a partir do decreto $\mathrm{n}^{\circ}$ 528 de 9 de março de 1964 . Até então, a competência do juiz administrativo colombiano somente se afirmava nos casos expressamente previstos pelo legislador. Não havia regra geral atribuindo-lhe todo o contencioso relativo às ações e omissões da administração pública. Com esse decreto de 1964, a associação juiz administrativo / ações-omissões da administração pública foi claramente posta no artigo 20, segundo o qual "[l] a jurisdicción contencioso administrativa está instituida para definir los negocios originados en las decisiones que tome la administración, en las operaciones que ejecute y en los hechos que ocurran con motivo de sus actividades".

$\mathrm{O}$ mesmo decreto previu, pela primeira vez, um tribunal independente para resolver os conflitos de competência entre o juiz ordinário e o juiz administrativo ${ }^{21}$. Essa prerrogativa permanecera, durante meio século, nas mãos da Corte Suprema de Justicia, o que era, sem dúvida, um elemento que lhe permitia afirmar sua preeminência face ao Consejo de Estado. Ao colocar um fim nessa primazia da Corte Suprema, o decreto procurou fazer com que a competência geral então conferida ao juiz administrativo conduzisse, de fato, a que todo o contencioso relativo às ações e omissões da administração pública ficasse nas mãos do juiz administrativo.

Percebe-se claramente que estas inovações fizeram com que as ações populares previstas pelo código civil perdessem progressivamente seu interesse

20 Corte Suprema de Justicia, acórdão de 6 de agosto de 1947, in Gaceta Judicial, t. LXIII, p. 244-246, esp. p. 246.

21 O decreto de 9 de março de 1964 tinha criado um "Tribunal de conflictos" para exercer esta competência, que foi transferida para o Tribunal disciplinario através de um acto legislativo de 1968 (art. 73) e, mais tarde, ao Consejo superior de la judicatura, por meio da reforma constitucional de 1979 (art. 44). 
face às especificidades da distribuição de competências jurisdicionais. Essas ações somente seriam admissíveis se, de um lado, o comportamento litigioso fosse de origem puramente "privada", ou seja, não suscetível de ser vinculado ao Estado e se, de outro lado, nenhum ato administrativo autorizasse este comportamento. Ora, em razão do desenvolvimento do Estado ao longo do século xx, era bastante difícil que um ato suscetível de afetar indivíduos indeterminados (art. 2359 do código civil) escapasse dessa dupla condição.

\section{CONCLUSÃO}

A particularidade do código civil colombiano de prever as ações populares não resistiu ao desenvolvimento do direito administrativo, caracterizado pela afirmação da exclusividade da administração pública na gestão dos bens de uso público e pela criação da jurisdição do contencioso administrativo.

Apesar dos pontos de partida diferentes assumidos nos respectivos códigos civis, Brasil e Colômbia acabaram tomando uma direção similar. No Brasil, a fim de evitar a duplicidade de meios para atingir o mesmo resultado, os redatores do código de 1916 optaram por não prever as ações populares, deixando às autoridades administrativas a tarefa de tomar as decisões relativas aos bens de uso público. Na Colômbia, o desenvolvimento do direito administrativo levou a Corte Suprema de Justicia, em um primeiro momento, a admitir as ações populares apenas nos casos expressamente previstos e, em um segundo momento, a não admitir as ações populares em que se pretendesse impor comportamentos às autoridades administrativas - o que levou, a exemplo do caso brasileiro, a deixar nas mãos da administração pública a tarefa de tomar as decisões relativas aos bens de uso público.

\section{BIBLIOGRAFÍA}

Bello, Andrés. Obras completas. Vol. XI. Proyectos de código civil. Vol. XII. Proyecto de código civil (1853). Santiago: Pedro G. Ramirez, 1887.

Bevilacqua, Clóvis. Teoria geral do direito civil, 2. ed. Rio de Janeiro: Editora Rio, 1980.

Corte Suprema de Justicia. Acórdão de 24 de setembro de 1891, in Gaceta Judicial, t. VI, p. 333-335.

Corte Suprema de Justicia. Acórdão de 23 de abril de 1941, in Gaceta Judicial, t. Li, p. 437-456.

Corte Suprema de Justicia. Acórdão de 7 de julho de 1942, in Gaceta Judicial, t. LiII, p. $231-240$

Corte Suprema de Justicia. Acórdão de 6 de agosto de 1947, in Gaceta Judicial, t. LXiII, p. 244-246. 
Guayacán Ortiz, Juan Carlos. Las acciones populares y de grupo frente a las acciones colectivas. Bogotá: Universidad Externado de Colombia, 2013.

Gusmão, Manuel Aureliano de. Processo civil e commercial. 4. ed. São Paulo: Saraiva, 1939.

SARmiento, Germán. Las acciones populares en el derecho privado colombiano. Bogotá, 1988. 